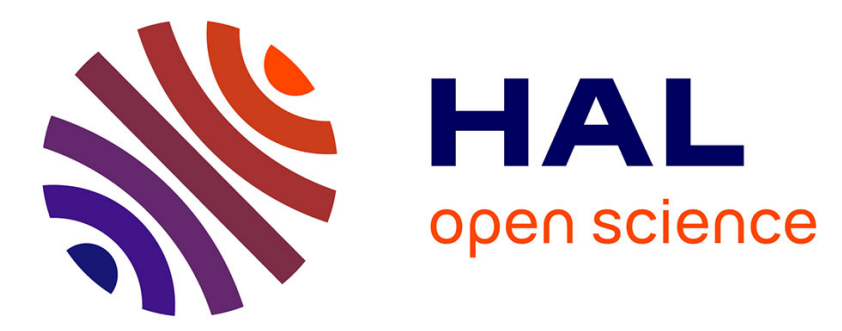

\title{
Influence of Water on Alkali-Silica Reaction: Experimental Study and Numerical Simulations
}

Stéphane Poyet, Alain Sellier, Bruno Capra, Geneviève Thèvenin-Foray, Jean-Michel Torrenti, Hélène Tournier-Cognon, Eric Bourdarot

\section{- To cite this version:}

Stéphane Poyet, Alain Sellier, Bruno Capra, Geneviève Thèvenin-Foray, Jean-Michel Torrenti, et al. Influence of Water on Alkali-Silica Reaction: Experimental Study and Numerical Simulations. Journal of Materials in Civil Engineering, 2006, 18 (4), 10.1061/(ASCE)0899-1561(2006)18:4(588) . cea-01272814

\section{HAL Id: cea-01272814 https://hal-cea.archives-ouvertes.fr/cea-01272814}

Submitted on 11 Feb 2016

HAL is a multi-disciplinary open access archive for the deposit and dissemination of scientific research documents, whether they are published or not. The documents may come from teaching and research institutions in France or abroad, or from public or private research centers.
L'archive ouverte pluridisciplinaire HAL, est destinée au dépôt et à la diffusion de documents scientifiques de niveau recherche, publiés ou non, émanant des établissements d'enseignement et de recherche français ou étrangers, des laboratoires publics ou privés. 
Final draft of the article:

"Influence of water on Alkali-Silica Reaction: experimental study and numerical simulations"

Published in the Materials Journal of ASCE, please visit http://dx.doi.org/10.1061/(ASCE)0899-1561(2006)18:4(588) or the Civil Engineering Database (http://cedb.asce.org/) for the copyedited version. 


\title{
Influence of water on Alkali-Silica Reaction: experimental study and numerical simulations
}

\author{
Stéphane Poyet ${ }^{1}$ - Alain Sellier ${ }^{2}$ - Bruno Capra $^{3}$ - Geneviève Thèvenin-Foray ${ }^{4}$ \\ Jean-Michel Torrenti ${ }^{5}$ - Hélène Tournier-Cognon ${ }^{6}$ - Eric Bourdarot ${ }^{7}$
}

\begin{abstract}
Alkali-Silica Reaction (ASR) is a concrete pathology due to chemical reactions involving reactive silica from reactive aggregates and the inner solution of concrete. Main effects are swelling, cracking and the reduction in the mechanical properties of affected concretes. Water is very important for ASR, the more available water the more expansion and degradation. This article presents new laws for the modelling of the influence of water upon ASR. They are based on experimental results and then used to simulate results taken out of scientific literature.
\end{abstract}

Keywords: concrete durability, Alkali-Silica Reaction, swelling, water, modelling, numeric simulations.

\section{Introduction}

Alkali silica reaction (ASR) is a world wide known concrete pathology. It is due to chemical reactions between amorphous or badly crystallized silica and ions from the interstitial solution (hydroxyls, alkalis and calcium ions). It leads to progressive destruction of reactive aggregates, precipitation of reaction products called "gels" which composition may vary a lot. It creates local variations in dimension.

ASR affected concrete structures have to cope with displacements, structural deformations, decrease of rigidity and sometimes pull-outs and collapse of mechanical resistance. Service of the structure may be severely affected.

After more than 60 years of research, the knowledge gained on reaction mechanisms did allow researchers and recommendation committees to edit rules to prevent new ASR cases (Ministère de l'Equipement 1994, Mather 1994). Unfortunately, from now on there has been no way to stop the reaction or to cure an affected structure. There are many ASR affected structures around the world for which periodical repairs and preventive maintenance policies cost a lot of money. Their managers need predictive tools to determine rate and end value of swelling in order to determine frequency, effectiveness of maintenance operations and effective economic life of structure.

The aim of our work is to provide a robust and safety modeling able to take account for the influence of hydric history on free ASR swelling. In a first part of this paper we present a non exhaustive literature review, afterward our experimental program is presented, the proposed modeling is then presented fitted on a the first part of the experimental program and tested on a second part and on literature data.

\section{Literature review}

\section{Experimental approach}

To initiate and develop Alkali-Silica-Reaction, soluble alkalis (sodium or potassium), reactive silica from aggregates and sufficient water must come into contact. Water plays two roles in this reaction:

1 CEA Saclay, DEN/DANS/DPC/SCCME/LECBA, B158, 91191 Gif sur Yvette, France. E-mail: stephane.poyet@cea.fr

2 Professor, LMDC, INSA - UPS, 135 avenue de Rangueil, 31077 Toulouse cedex 4, France. E-mail: alain.sellier@insa-toulouse.fr

3 Scientific director, Oxand SA, 36bis avenue Franklin Roosevelt, 77210 Avon, France. E-mail: bruno.capra@oxand.com

${ }^{4}$ Professor, Université Lyon 1 - L2MS - PETRA GC, 82 boulevard Niels BOHR - Domaine scientifique de la DOUA - 69622 Villeurbanne Cedex, France. E-mail: g.foray@iutagc.univ-lyon1.fr

${ }^{5}$ Professor, IRSN, BP17, 92262 Fontenay aux Roses cedex, France. E-mail: jean-michel.torrenti@irsn.fr

${ }^{6}$ Research Scientist, DER - EDF, Les Renardières, Route de Sens, Ecuelles, 77818 Moret sur Loing, France. E-mail: helene.cognon@edf.fr

${ }^{7}$ Research Scientist, Direction de 1'Equipement, CIH, Savoie Technolac, 73373 Le Bourget du Lac, France. E-mail: eric.bourdarot@edf.fr 
- transport medium of ionic species involved in ASR,

- reactant (water is included in the amorphous gel formed).

Influence of water is therefore a matter of concern in ASR research. H. E. Vivian (1981) observed that expansion measured on mortar samples affected by ASR decreases with the available water quantity. He therefore stated that drying affected mortar samples could stop ASR reaction. This was confirmed by several researchers working with different mix compositions and specific tests protocols to accelerate ASR reaction, Olafsson (1986), Tomosawa et al. (1989) and Kurihara et al. (1989). Table 1 and Fig. 1 sum up their respective test conditions and results.

Fig. 1 does not show a straight correlation between external relative humidity and ASR expansion. This may be due to the duration of Olafsson (for $23^{\circ} \mathrm{C}$ ) and Kurihara $40^{\circ} \mathrm{C}$ tests which are to short to reach the maximal ASR expansion (Table 1). The computed deformations percentage being therefore not representative of ASR development. For a given cementitious material, ASR swelling is directly correlated with mass variations. The higher the mass gain, the more expansion (Tomosawa et al. 1989, Kurihara et al. 1989 and Larive et al. 2000). Moreover, water intake history is very important for ASR (Vivian 1981, Larive et al. 2000). Irregular external water supplies seem to irreversibly affect concrete expansion. Larive et al. $(1998,2000)$ submitted two series of specimens to different water supplies. The first ones were dried (561 days) and then immersed into water; the final expansion was about $0.45 \%$. The second ones were kept without significant water exchange (447 days) and then immersed into water; the final expansion was about $0.15 \%$.

In addition, Tomosawa et al. (1989) and Kurihara et al. (1989) have shown that below a water content threshold (water content within the sample with respect to the dry weigth of the sample) ASR expansion is inhibited. Unfortunately the value of this water content threshold (4\% of the dry mass for Tomosawa et al., $8 \%$ of the dry mass for Kurihara et al. and $0.15 \%$ of weigth loss for Larive et al.) depends on the affected material, the initial water content within the samples.

According to Nilsson (1983) there is no ASR degradation when the external relative humidity drops below $80 \%$. Ludwig (1989) defines this RH (Relative Humidity) threshold between $80 \%$ and $85 \%$ for a temperature equal to $20^{\circ} \mathrm{C}$. The value of this threshold depends on temperature. According to Olafsson (1986) it falls from about $80 \%$ at $23^{\circ} \mathrm{C}$ to $75 \%$ at $38^{\circ} \mathrm{C}$. According to Tomosawa et al. (1989) and Kurihara et al. (1989), it is below $75 \%$ at $40^{\circ} \mathrm{C}$ (see Fig. 2). Fig. 2 shows that there is no linear relation between temperature and relative humidity threshold.

Moreover, variations of external relative humidity and temperature induce transport of ionic species and local differences of concentration within the material (Xu and Hooton 1993, Rivard et al. 2003). These phenomena may modify the evolution of ASR swelling (Nishibayashi et al. 2003).

\section{Review of existing modelings}

Water has a great influence on kinetics of ASR as well on swelling value. A few models are able to take into account the role of water. The model proposed by Nielsen et al. (1993) relates the value of ASR swelling to the relative humidity within pores of the material. The law used is empirical (Fig. 3). It is based on the observations of L. O. Nilsson (1983).

Capra and Bournazel (1998) compute ASR swelling using the following equation:

$$
\varepsilon^{a s r}(t, h, T, \sigma)=\varepsilon^{100 \%}(t) f(h) g(T, \sigma)
$$

- $\varepsilon^{100 \%}(t)$ is the free swelling observed on sample at $100 \% \mathrm{RH}$,

- $h$ is the relative humidity in the material pores,

- $g(T, \sigma)$ and $f(h)$ are two functions, that describe the influence of temperature, stress and relative humidity on ASR swelling. The setting of the last function is made using values issued from literature (see Fig. 3).

$$
f(h)=\left(\frac{h}{100}\right)^{8}
$$

According to the two models proposed by Bažant and Steffens (2000) and Li et al. (2000, 2002), ASR does firstly result in a dry gel that matures with time. This maturation (imbibition of the dry gel in order to create a fluid) is described by a first order kinetic. Bažant and Steffens (1999) state that the capture of some water by the gel may only occur above a relative humidity threshold in the pores. This threshold value is supposed to be equal to 85\% (Fig. 3, this curve is theoretical and does not stand represent experiment results). Li et al. (2000, 2002) do not define any threshold value. In their model, the ASR gel incorporates water in a continuous way depending on water availability. All the authors consider that the amount of water which influences ASR is the available water within affected material near to reaction sites. To use a model for extrapolation purposes, i.e. for prediction of ASR swelling, one must therefore know quite exactly the water distribution within the material.

Our purpose is to develop a modeling that relates the amount of available water within affected materials to the kinetics and the value of the free swelling induced by ASR. A first experimental program is designed to calibrate the 
modeling constitutive laws. A second experimental program and some experimental works issued from a literature review are used to check whether the model is sound and consistent.

\section{Experimental campaign}

The experimental campaign aims at studying the evolution of kinetics and maximal expansion induced by ASR on mortar samples kept at different relative humidities (Poyet, 2003). Two series of experiments are undertaken. In the first one (subsequent called RH_constant) the external relative humidity remains constant. In the second one (called RH_variable) the specimens undergo cyclic changes in relative humidities. Moreover, two types of cycles are studied short ones and long ones (see Fig. 4).

The specimens are cylindrical $(16 \mathrm{~cm}$ height with a diameter of $2 \mathrm{~cm})$. They are cast and kept vertically. ASR expansion is measured vertically as well. Two compositions are cast including different aggregates: a reactive limestone sand (the same as the one studied by Guédon-Dubied et al. 2000), and an innocuous limestone one, (Table 2). The two sand particle size distributions are corrected in order to be similar. An ordinary Portland cement is used. The mixing water is de-ionized water at ambient temperature. The alkali level is adjusted by adding sodium hydroxide pellets into the mixing water. More data about these experiments can be found in (Poyet, 2003).

The specimens are removed from their mould after 10 days at $20^{\circ} \mathrm{C}$ wrapped in a sealing film. Afterwards, they are kept at $60^{\circ} \mathrm{C}$ and submitted to the desired external relative humidity. Mass and length of sample are measured up to 200 days. The presented results (mean value) are computed using four identical specimens (the standard deviation is mostly less than $0.04 \%$ ). Target relative humidity in each chamber is obtained by a saturated saline solution. The chambers are agitated every day in order to be sure that the humidity is uniform within the whole chamber. This method has already been used by other authors and recently by the followings Baroghel-Bouny et al. (2000), Raoof (1998) and Delage et al. (1998). The external relative humidites imposed to the first series are between 59\% RH and $100 \%$ RH. Six levels are used (Table 3).

The external relative humidity history for cyclic experiments are pictured in Fig. 4. The 28 day cycles are long enough to dry the material at each cycle, whereas the 14 day ones are short enough to remain in an intermediate state: partial saturation. Cycles are calculated so that a 59 day old sample has spent in both cases the same time in $98 \%$ RH chamber ( 28 days for the long cycles, $2 * 14$ days for the short one).

\section{RH_constant experiments}

Relative mass variations of specimens are presented on Fig. 5. The mass variations are ranged between a loss about $2.5 \%$ for $59 \% \mathrm{RH}$ to a gain $2.4 \%$ for $100 \% \mathrm{RH}$ (Table 4 ). The mean mass of $82 \% \mathrm{RH}$ samples remains constant over the test. It means that the initial relative humidity within pores of the specimens is $82 \%$.

Expansion generated by ASR is calculated by deducting the expansion of inert specimens (including non-reactive sand) from the expansion of reactive specimens (Fig. 6). The higher the external relative humidity, the more and the faster ASR expansion. These results confirm the observations of previous experiments (Olafsson 1986, Tomosawa et al. 1989 and Kurihara et al. 1989). Moreover, they clearly show that there is a correlation between water intake and ASR expansion (Table 4) as it has already been pointed out by Vivian (1981) and Larive et al. (2000).

Nevertheless, the expansion generated by ASR for the specimens submitted to $\mathrm{RH}=100 \%$ is inferior to the one for $\mathrm{RH}=96 \%$ whereas water intake is superior (Fig. 6:). This is due to the leaching of alkalis in consequence to the condensation of pure water on the external surface of the samples which leads to the reduction of ASR expansion. This fact has already been pointed out (Rogers and Hooton 1991 and Wiecker et al. 2000). The results for RH=76\% are not reproduced because they are irrelevant (alkaline pollution of the specimens because of contact with the solution).

In addition, for a temperature equal to $60^{\circ} \mathrm{C}$, the $\mathrm{RH}$ threshold under which ASR swelling is inhibited seems to be less than $59 \%$ since the ASR expansion of specimens submitted to $\mathrm{RH}=59 \%$ is about $0.06 \%$ after 100 days.

\section{RH_variable experiments}

Fig. 7 presents the mean mass variations of the specimens for 14 and 28 day cycle. As expected samples that undergo the 28 day cycle reach a mass equilibrium while the ones that undergo the 14 days cycle remains partially saturated.

Cyclic RH mass variation are included in a $[-5.0 \% ; 0.0 \%]$ range that differ from the $[-2.5 \% ; 2.4 \%]$ range found for constant RH specimens. The width is the same but the mean values are distinct. The specimens from both series were not cast the same day. They were respectively cast in summer and in winter for RH_constant and RH_variable series. This could explain the difference on the initial water content.

One can notice that the first drying cycle always differs from the others. For short cycles, a $4.0 \%$ mass loss is associated to the dry end of the first cycle. This value becomes higher for all the following cycle: $4.8 \%$. For long 
cycle, a 5.0\% mass loss is associated to the first cycle. This first value is a maximum and is not reached again in the following cycle. The mass variation goes only down than to $4.3 \%$. This might be explained by precipitation reaction or maturity evolution that modifies porosity.

Fig. 8 shows the ASR expansions. They are quite similar for both cycles up to 80 days. Afterwards expansion for short cycles seems to stop whereas expansion for long ones seems to keep on increasing. This should be confirmed by longer test duration.

For each drying part (short and long cycles), an extra shrinkage about $0.04 \%$ is recorded. Its origin is unknown. It might be that those ASR samples undergo two kinds of shrinkage:

- A shrinkage due to cement paste drying. This part does not appear here as the curves plotted are expansion generated by ASR only (deformations of a reactive sample minus deformations of a non reactive sample),

- A shrinkage due to water loss by the ASR gel. As the sample dries, ASR gels lose water. It comes that the ASR gel takes less volume. The pressure exerted on pore walls is relieved and the recorded deformation decreases.

Fig. 9 compares the expansion generated by ASR for cyclic RH and relevant constant RH. Given a date of test, ASR deformations for cyclic samples are always higher than the one for constant $59 \% \mathrm{RH}$ and lower than that of constant $96 \%$ RH.

At 20 days, deformations values are $0.01 \%$ for 28 days cycles, $0.04 \%$ for 14 days cycles, $0.05 \%$ for constant RH. This shows that for the same formulation, several specimens give different experimental results. Comparing those deformation values with the mass variation values, one can notice that those small expansion differences are only due to differences in water loss. This confirms that comparison between some expansion curves can not be done as a separate task. To analyze an ASR expansion curve, the mass variation curve and the initial water state of the sample are necessary.

\section{Conclusion about the experimental campaign}

Fig. 10 compares our results with the ones found in the literature. The new values obtained are within "the literature range". Nevertheless, the range of values found is too wide to state a law that relates ASR expansion to the relative humidity (external RH or within pores). Moreover, the available water content within the affected material is neither constant nor uniform versus time. It is thus compulsory to take it into account in order to propose a hydro-chemomechanical method to estimate the swelling generated by ASR.

\section{Presentation of the modeling}

In the modeling proposed herein, we have chosen to describe the available water within affected concrete by the means of the Saturation Ratio "Sr". It represents the pore water filling percentage. We define a dimensionless variable A to monitor the progress of ASR. The values of $A$ are ranged between 0 and 1 . $A$ only depends on time $t$ and saturation ratio $S r$. We suppose that for any given value of $S r$ below 1, A cannot reach its maximum value. Corresponding ASR swelling thus depends on external relative humidity and water intake as it has already been observed experimentally. The ASR advancement $A$ and the free expansion induced by ASR $\varepsilon^{\text {asr }}$ are supposed to follow the following original laws:

$$
\dot{A}(S r, t)=\frac{\partial A}{\partial t}(S r, t)=\alpha_{0} \alpha(S r)[\beta(S r)-A(S r, t)]
$$

- $\alpha_{0}$ is a constant which characterizes the kinetics of ASR,

- $\quad \beta$ is a function which gives the maximal advancement that the ASR can reach. It is a function of the saturation ratio $S r$. It only depends on $S r$. Its values are ranged between 0 (for $S r=0$ ) and 1 (for $S r=1$ ). Its form has to be fitted on experimental data. The physic meaning of $\beta$ is that the involved chemical phenomena are limited around residual saturated zones of concrete.

- $\quad \alpha$ is another function which alters the kinetics of ASR as a function of the saturation ratio Sr. Its value are always between 0 (for $S r=0$ ) and 1 (for $S r=1$ ). Its mathematical expression has also to be defined. The physic meaning of $\alpha$ is that necessary chemical species for ASR diffuse towards reactive sites and that drying slows diffusion.

The ASR free swelling $\varepsilon^{a s r}$ is linked to the advancement $A$ by the following:

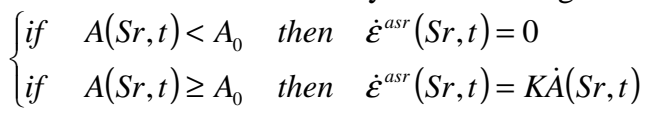


- $\quad K$ is a parameter that relates the expansion to the advancement. It depends on the mechanical properties of the affected material, the quantity and the reactivity of the reactive aggregates used, the amount of available alkalis, ... etc.

- $\quad A_{0}$ stands for the minimal ASR advancement necessary to initiate swelling (i.e. it represents the quantity of gel to fill the available porous volume around reactive aggregates).

When the saturation ratio $S r$ is a function of time $t$, one cannot solve analytically the equations (3) and (4). An incremental process is necessary to integrate these expressions. For example, we can assume that $S r$ is constant between two close times $t$ and $t+\delta t$ :

- $\quad \delta t$ is the time increment $(\delta t<<t)$,

$$
A\left(\overline{S r}, t_{1}\right)=\beta(\overline{S r})-[\beta(\overline{S r})-A(\overline{S r}, t)] \exp \left[-\alpha_{0} \alpha(\overline{S r})\left(t_{1}-t\right)\right]
$$

- $\overline{S r}$ is the mean value of $S r$ within the range $[t ; t+\delta t]$,

- $t_{1}$ is a time included in the domain $[t ; t+\delta t]$.

$\alpha$ and $\beta$ laws are supposed to follow:

$$
\alpha(S r)=\left(\frac{\left\langle S r-S r_{0}^{a}\right\rangle^{+}}{1-S r_{0}^{\alpha}}\right)^{m_{\alpha}} \text { and } \beta(S r)=\left(\frac{\left\langle S r-S r_{0}^{\beta}\right\rangle^{+}}{1-S r_{0}^{\beta}}\right)^{m_{\beta}}
$$

- $\langle X\rangle^{+}$represents the positive part of $X$,

- $S r_{0}^{\alpha}$ and $S r_{0}^{\beta}$ are thresholds below which the functions are zero,

- $\quad m_{\alpha}$ et $m_{\beta}$ stand for possible non linearity.

A goal of the experimental program is then to characterize both functions $\alpha$ and $\beta$. This implies in the one hand the determination of the two thresholds $S r_{0}^{\alpha}$ and $S r_{0}^{\beta}$, and in the other hand the determination of both exponents $m_{\alpha}$ and $m_{\beta}$.

\section{Application of the modeling}

\section{Determination of the saturation ratio $S r$ and corresponding ASR expansion}

The input data of the model to predict both kinetics and maximal ASR induced expansion is the saturation ratio $S r$ and the swelling parameters $\alpha_{0}, A_{0}$ and $K$. The main goal of this work is to fit the laws $\alpha$ and $\beta$, so we need to know the more accurately possible the saturation ratio $S r$. It could be estimated using a water transport calculation.

In our case (with available mass variations) the determination of the values of $S r$ in every point of the sample is based on some previous works by Benboudjema et al. (2003) and Torrenti et al. (1999). The fields of saturation ratio $\mathrm{Sr}$ are estimated thanks to a finite element calculus (French code CAST3M). The variation of the diffusivity with the hydric state of the material are included (Xi et al. 1994).

Once the fields of saturation ratio $S r$ are determined in every location in the sample, the fields of reaction advancement $A$ and ASR free swelling $\varepsilon^{a s r}$ are computed by the means of the formulas (3) and (4). The supplementary drying shrinkage observed experimentally (Fig. 8) is supposed to be proportional to ASR expansion and capillary pressure Pc:

$$
\varepsilon_{s h r}^{a s r}(S r, t)=-c \varepsilon^{a s r}(S r, t)\left\langle\frac{P c-P c_{0}}{P c_{0}}\right\rangle^{+}
$$

The capillary pressure $P c$ within pores depends on the saturation ratio $S r$ (Van Genuchten 1980 and BaroghelBouny et al. 2000):

$$
P c(S r)=-a\left(S r^{-b}-1\right)^{1-\frac{1}{b}}
$$

The swelling (ASR and supplementary shrinkage) of each specimen is then computed thanks to an elastic approach:

$$
\varepsilon=\varepsilon^{e}+\varepsilon^{a s r}+\varepsilon_{\text {shr }}^{a s r} \quad \sigma=\lambda \operatorname{tr}\left(\varepsilon^{e}\right) I+\mu \varepsilon^{e}
$$

This elastic approach neglect induced damage and lead to a slight overestimation of $K$.

\section{Simulation of $\mathbf{R H}$ _constant experiments}

The saturation ratio $S r$ is estimated on the basis of experimental mass variations (Fig. 11). The ASR swelling parameters $\left(\alpha_{0}, A_{0}\right.$ and $\left.K\right)$ are identified thanks to experimental expansions (Table 5). The thresholds $S r_{0}^{\alpha}, S r_{0}^{\beta}$ and 
the exponents $m_{\alpha}$ et $m_{\beta}$ for the laws $\alpha$ and $\beta$ are determined thanks to a parametric study in order to fit in the best way possible the experimental ASR expansions (see the comparison between experimental and predicted ASR expansions on Fig. 12). The laws $\alpha$ and $\beta$ thus obtained are linear without threshold (Table 6).

\section{Validation of the modeling}

The laws $\alpha$ and $\beta$ have been fitted thanks to the results of RH_constant experiments. They are supposed to be characteristic of alkali-silica reaction. They are assumed neither to depend on affected concrete, reactive aggregates nor temperature. In order to verify this assumption, the model thus obtained $(\alpha(S r)=S r$ and $\beta(S r)=S r)$ is used to reproduce the results of different experiments: RH_variable, Tomosawa 1989, Kurihara 1989 and Larive 2000 (mortar and concrete, different reactive aggregates and different temperatures). Full results can be found in (Poyet, 2003), only the simulations for RH_variable, Tomosawa et al. (1989) and Larive et al. (2000) are presented here.

\section{Simulation of $\mathbf{R H}$ _variable experiments}

The modeling is applied in order to reproduce the results of the second experimental campaign: RH_variable experiments. Like before, the saturation ratio is estimated on the basis of experimental mass variations (Fig. 13). Corresponding ASR expansion is then computed using the incremental process described above (Fig. 14). Once fitted, the proposed modeling is able to correctly predict both ASR expansion rate and maximal value. The swelling parameters $\left(\alpha_{0}, A_{0}\right.$ and $\left.K\right)$ are the same as for RH_constant simulations (Table 5).

\section{Simulation of experiments taken out of literature}

Several authors have published experimental results on influence of water on ASR expansion. The experimental results of Tomosawa et al. (1989), Kurihara et al. (1989) and Larive et al. (1998, 2000) were successfully used to validate our model (Poyet 2003). The results of the simulations of Tomosawa and Larive experiments are presented in this paper. Reactive specimens undergo different water intakes. Their length and mass variations are measured. As before, the saturation ratio $\mathrm{Sr}$ is estimated on the basis of the experimental mass data (see Fig. 15 and Fig. 16). Expansion generated by ASR is then computed and compared to the experimental data (see Fig. 15 and Fig. 16). The swelling data used to simulate the results of the experiments of Tomosawa et al. (1989) and Larive et al. (2000) are presented in the Table 7.

More simulations have been made; they are presented in Poyet (2003). The model gives satisfactory results according to the precision on the description/prediction of the saturation ratio $\mathrm{Sr}$.

\section{Conclusions}

A new modeling of Alkali-Silica Reaction is presented in this paper. It allows to takes into account the amount of available water within affected material to estimate the free expansion generated by ASR. The saturation ratio $S r$ is chosen as parameter. The modeling allows predicting rate of swelling and end value of swelling generated by ASR on any structure.

To use this modeling, one has first to fit three swelling parameters $\left(A_{0}, \alpha_{0}\right.$ and $\left.K\right)$. They are material parameters that define the swelling properties of the studied reactive material (ASR kinetics, maximal expansion and latency time).

Moreover the overall water distribution within the sample must be known at each stage of the reaction. This implies to define and compute water diffusion within the affected sample/structure versus time. As a consequence, for any affected structure and reactive material, the expansion generated by ASR is governed by the evolution of the saturation ratio $\mathrm{Sr}$.

The results of a first series of experiments, (cylindrical samples maintained within constant RH -6 different levels), are used to fit the modeling constitutive laws (laws $\alpha$ and $\beta$ which describe the influence of water on ASR kinetics and maximal value of swelling as functions of $\mathrm{Sr}$ ). These functions do not depend on the studied material.

The modeling is then used to reproduce the results of other experiments (specimens submitted to cyclic water intake and experiments taken out from literature). Experimental results and numerical simulations are in good accordance. This modeling will also be used to simulate ASR affected beams submitted to an external moisture gradient (Multon et al. 2003, 2004). Full results will be presented in a following article. 


\section{Acknowledgements}

This study was performed as collaboration between the Laboratoire de Mécanique of the University of Marne la Vallée (LaM - UMLV) and Electricité de France (DER and CIH from EdF). The first author would like to thank Hélène Tournier and Eric Bourdarot from EdF for their financial and scientific support.

\section{References}

Baroghel-Bouny B.,. Mainguy M., Lassabatère T. and Coussy O. (2000), "Characterization and identification of equilibrium and moisture transfert properties for ordinary and high performance cementitious materials", Cement and Concrete Research, 29(8), 1125-1238.

Bažant Z. P. and Steffens A. (2000), "Mathematical model for kinetics of alkali-silica reaction in concrete", Cement and Concrete Research, 30(3), 419-428.

Benboudjema F., Meftah F. and Torrenti J.-M. (2003), “A unified approach for the modeling of drying shrinkage and basic creep of concrete", Proceedings of the Euro-C Computational Modeling of Concrete Structures, Pongau, Austria, 391-400.

Capra B. and Bournazel J.-P. (1998), "Modeling of induced mechanical effects of alkali-aggregate reactions", Cement and Concrete Research, 28(2), 251-260.

Delage P., Howat M. D. and Cui Y. J. (1998), "The relationship between suction and swelling properties in a heavily compacted unsaturated clay", Engineering Geology, 50(1-2), 31-48.

Guédon-Dubied J.-S., Cadoret G., Durieux V., Martineau F., Fasseu P. and Van Overbecke V. (2000), "Study on Tournai limestone in Atoing Cimescaut quarrypetrological, chemical and alkali reactivity approach", Proceedings of the $11^{\text {th }}$ International Conference on Alkali Aggregate Reaction in concrete, Québec City, Canada, 335-344.

Kurihara T. and Katawaki K. (1989), "Effects of moisture control and inhibition on alkali silica reaction", Proceedings of the $8^{\text {th }}$ International Conference on Alkali Aggregate Reaction in concrete, Kyoto, Japan, 629634.

Larive C. (1998), “Apports combinés de l'expérimentation et de la modélisation à la compréhension de l'alcaliréaction et de ses effets mécaniques", OA 28, Presses du Laboratoire Central des Ponts et Chaussées, Paris, France (in french), 278p.

Larive C., Laplaud A. and Coussy O. (2000), "The role of water in alkali-silica reaction", Proceedings of the $11^{\text {th }}$ International Conference on Alkali Aggregate Reaction in concrete, Québec City, Canada, 61-69.

Li K., Ulm F.-J., Coussy O., Larive C. and Fan L. (2000), "Chemoelastic modelling of alkali-silica reaction in concrete", Proceedings of the $11^{\text {th }}$ International Conference on Alkali-Aggregate Reaction in concrete, Québec City, Canada, 989-998.

Li K. and Coussy O. (2002), «Evaluation de l'état mécanique des ouvrages dégradés par la réaction alcaligranulat », Revue française de Génie Civil, 6, 835-852.

Ludwig U. (1989), "Effects of environmental conditions on alkali-aggregate reaction and preventive measures", Proceedings of the $8^{\text {th }}$ International Conference on Alkali Aggregate Reaction in concrete, Kyoto, Japan, 583596.

Mather B. (1999), "How to make concrete that will not suffer deleterious alkali-silica reaction », Cement and Concrete Research, 29(8), 1277-1280.

Ministère de l'Equipement (1994), "Recommandations pour la prévention des désordres dus à l'alcali-réaction", Presses du Laboratoire Central des Ponts et Chaussées (in french), Paris, France.

Multon S., Seignol J.-F. and Toutlemonde F. (2003), "Large girders subjected to Alkali-Silica Reaction", Proceedings of the $6^{\text {th }}$ CANMET ACI International Conference on Durability of Concrete, Thessalonikki, Greece, 299-318.

Multon S., Merliot E., Joly M. and Toulemonde F. (2004), "Water distribution in beams damaged by alkali-silica reaction: global weighing and local gammadensitometry", Materials and Structures, 37, 282-288.

Nielsen A., Gottfredsen F. and Thogersen F. (1993), "Development of stresses in concrete structures with alkalisilica reactions", Materials and Structures, 26(157), 152-158.

Nilsson L. O. (1983), "Moisture effects on the Alkali-Silica Reaction”, Proceedings of the International Conference on Alkalis in Concrete, Copenhagen, Denmark, 201-208.

Nishibayashi S., Yamura K. and Sakata K. (1989), "Research on influence of cyclic wetting and drying on alkaliaggregate reaction", Proceedings of the $8^{\text {th }}$ International Conference on Alkali Aggregate Reaction in concrete, Kyoto, Japan, 617-622. 
Olafsson H. (1986), "The effect of relative humidity and temperature on alkali expansion of mortar bars", Proceedings of the $7^{\text {th }}$ International Conference on Alkali Aggregate Reaction in concrete, Ottawa, Canada, 461465.

Poyet S. (2003), "Etude de la dégradation des ouvrages en béton atteints par la réaction alcali-silice : approche expérimentale et modélisation numérique multi-échelles dans un environnement hydro-chemo-mécanique variable", Ph-D thesis Université de Marne la Vallée, France (in french), 241p.

Raoof A. (1998), “Adsorption, distribution et dynamique de l'eau dans les milieux poreux", SI 6, Presses du Laboratoire Central des Ponts et Chaussées (in french), Paris, France, 196p.

Rivard P., Berube M. A., Ballivy G. and Ollivier J. P. (2003), "Effect of drying-rewetting on the alkali concentration of the concrete pore solution", Cement and Concrete Research, 33(6), 927-929.

Rogers C. A. and Hooton R. D. (1991), "Reduction in mortar and concrete expansion with reactive aggregates due to alkali leaching", Cement and Concrete Aggregates, 13(1), 42-49.

Tomosawa F., Tamura K. and Abe M. (1989), "Influence of water content of concrete on alkali-aggregate reaction", Proceedings of the $8^{\text {th }}$ International Conference on Alkali Aggregate Reaction in concrete, Kyoto, Japan, 881885.

Torrenti J.-M., Granger L., Diruy M. and Genin P. (1999) "Modeling concrete shrinkage under variable ambient conditions", ACI Materials Journal, 96(1), 35-39.

Van Genuchten M. T. (1980), "A closed form equation for predicting the hydraulic conductivity of unsaturated soils", Soils Science Society of America, 44, 892-898.

Vivian H. E. (1981), "The effect of drying on reactive aggregate and mortar expansions", Proceedings of the $5^{\text {th }}$ International Conference on Alkali Aggregate Reaction in concrete, Cape Town, South Africa, S252-28.

Wieker W., Hubert C., Heidemann D. and Ebert R. (2000), "Some experiences in chemical modelling of the alkalisilica reaction", Proceedings of the $11^{\text {th }}$ International Conference on Alkali Aggregate Reaction in concrete, Québec City, Canada, 119-128.

Xi Y., Bažant Z. P., Molina L. and Jennings H. M. (1994), "Moisture diffusion in cementious materials: moisture capacity and diffusivity", Advanced Cement Based Materials, 1(6), 258-266.

$\mathrm{Xu}$ Z. and Hooton R. D. (1993), "Migration of alkali ions in mortar due to several mechanisms", Cement and Concrete Research, 23(4), 951-961. 
Table 1: test conditions and main measurements for several authors

\begin{tabular}{|c|c|c|c|}
\hline Authors & Olafsson & Tomosawa et al. & Kurihara et al. \\
\hline Temperature & 23 and $38^{\circ} \mathrm{C}$ & $40^{\circ} \mathrm{C}$ & $40^{\circ} \mathrm{C}$ \\
\hline Sample shape & Prismatic & Prismatic & Unknown \\
\hline Dimensions & Unknown & $7.5^{*} 7.5^{*} 40 \mathrm{~cm}$ & Unknown \\
\hline Material & Mortar & Concrete & Mortar \\
\hline Duration & 22 months & 52 weeks & 12 weeks \\
\hline Results & Expansion & Expansion and mass & Expansion and Water content \\
\hline
\end{tabular}

Table 2: composition of the mortar

\begin{tabular}{|c|c|c|c|}
\hline \multirow{2}{*}{ Materials } & \multicolumn{2}{|c|}{ Quantity } & \multirow{2}{*}{ Units } \\
\cline { 2 - 3 } & Non reactive & Reactive & \\
\hline Cement & 537.8 & 537.6 & $\mathrm{~kg} / \mathrm{m}^{3}$ \\
\hline De-ionized water & 268.8 & 268.8 & $1 / \mathrm{m}^{3}$ \\
\hline Non reactive sand $[0-5 \mathrm{~mm}]$ & 1612.8 & 806.4 & $\mathrm{~kg} / \mathrm{m}^{3}$ \\
\hline Reactive sand $[0-5 \mathrm{~mm}]$ & - & 806.4 & $\mathrm{~kg} / \mathrm{m}^{3}$ \\
\hline $\mathrm{NaOH}$ & 9.9 & 9.9 & $\mathrm{~kg} / \mathrm{m}^{3}$ \\
\hline
\end{tabular}

Table 3: soluble salt used and relative humidity reached

\begin{tabular}{|c|c|c|}
\hline Soluble salt & Formula & $\begin{array}{c}\text { Relative } \\
\text { Humidity }\left(\mathbf{6 0}^{\circ} \mathbf{C}\right)\end{array}$ \\
\hline De-ionized water & $\mathrm{H}_{2} \mathrm{O}$ & $100 \%$ \\
\hline Potassium sulfate & $\mathrm{K}_{2} \mathrm{SO}_{4}$ & $96 \%$ \\
\hline Potassium nitrate & $\mathrm{KNO}_{3}$ & $82 \%$ \\
\hline Potassium chloride & $\mathrm{KCl}$ & $80 \%$ \\
\hline Sodium chloride & $\mathrm{NaCl}$ & $76 \%$ \\
\hline Sodium nitrite & $\mathrm{NaNO}_{2}$ & $59 \%$ \\
\hline
\end{tabular}

Table 4: mass variation and ASR expansion for different external Relative Humidities

\begin{tabular}{|c|c|c|c|c|c|c|}
\hline External RH & $100 \%$ & $96 \%$ & $82 \%$ & $80 \%$ & $76 \%$ & $59 \%$ \\
\hline Mass variation & $2.40 \%$ & $2.10 \%$ & $0.00 \%$ & $-0.98 \%$ & $-1.27 \%$ & $-2.51 \%$ \\
\hline ASR expansion & $0.24 \%$ & $0.28 \%$ & $0.19 \%$ & $0.14 \%$ & $0.11 \%$ & $0.03 \%$ \\
\hline
\end{tabular}

Table 5: swelling data used for the numerical simulations

\begin{tabular}{|c|c|c|c|}
\hline Data & $\boldsymbol{A}_{\boldsymbol{0}}$ & $\boldsymbol{\alpha}_{0}$ & $\boldsymbol{K}$ \\
\hline Value & 0.00 & 0.04 day $^{-1}$ & $0.35 \%$ \\
\hline
\end{tabular}

Table 6: definition of $\alpha$ (kinetics) and $\beta$ laws (expansion induced)

\begin{tabular}{|c|c|c|c|}
\hline \multicolumn{2}{|c|}{ Law $\boldsymbol{\alpha}(\mathbf{S r})$} & \multicolumn{2}{c|}{ Law $\boldsymbol{\beta}(\boldsymbol{S r})$} \\
\hline$S r_{0}^{\alpha}$ & $m_{\alpha}$ & $S r_{0}^{\beta}$ & $m_{\beta}$ \\
\hline 0 & 1 & 0 & 1 \\
\hline
\end{tabular}

Table 7: swelling data for the simulations of the experiments of Tomosawa et al. (1989) and Larive et al. (2000)

\begin{tabular}{|c|c|c|c|}
\hline Data & Tomosawa et al. & Larive et al. & Unity \\
\hline$\alpha_{0}$ & 0.011 & 0.02 & day $^{-1}$ \\
\hline$A_{0}$ & 0.25 & 0.35 & - \\
\hline$K$ & 0.265 & 0.35 & $\%$ \\
\hline
\end{tabular}




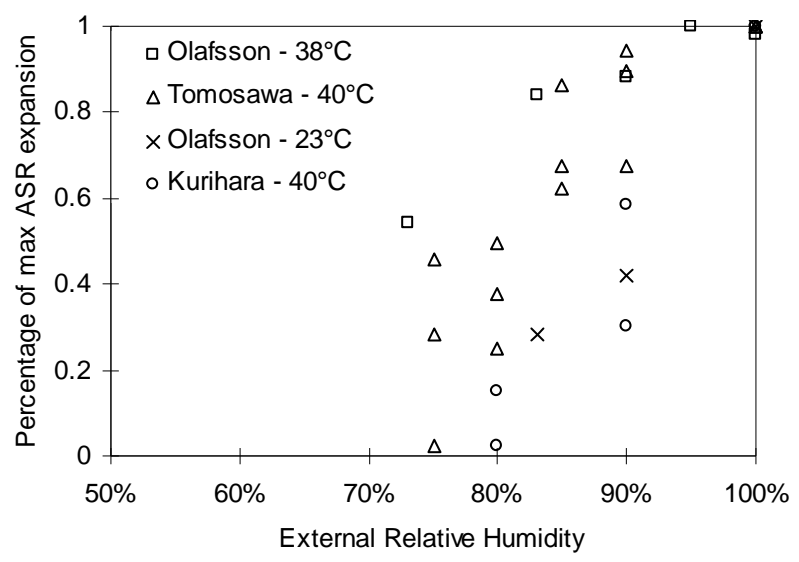

Fig. 1: evolution of maximal ASR expansion versus external relative humidity for several authors.

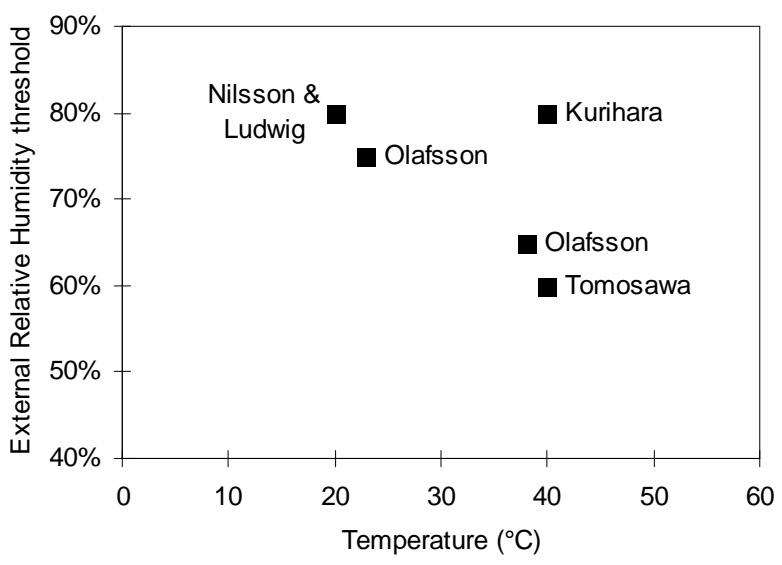

Fig. 2: evolution of the external relative humidity threshold as a function of temperature (from several authors).

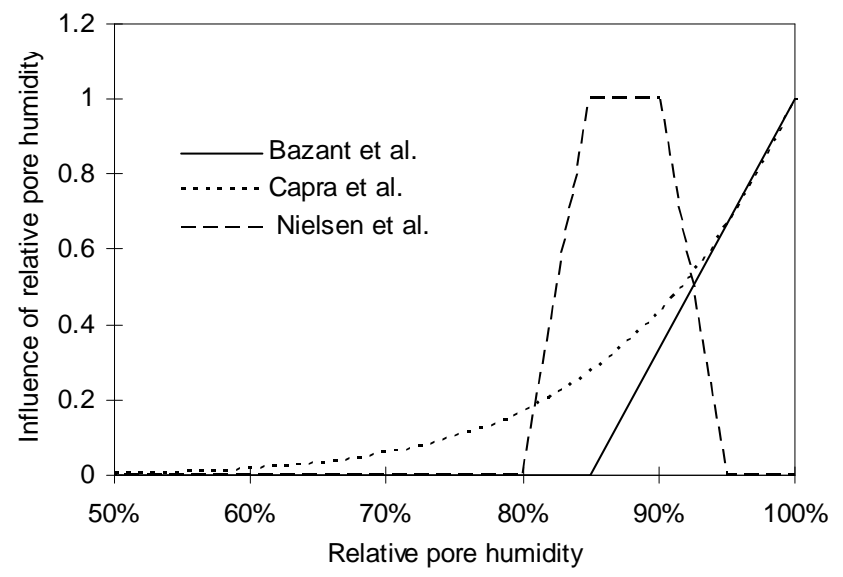

Fig. 3: influence of computed pore relative humidity on predicted expansion generated by alkali-silica reaction from Nielsen et al. (1993), Capra et al. (1998) and Bažant et al. (2000). 

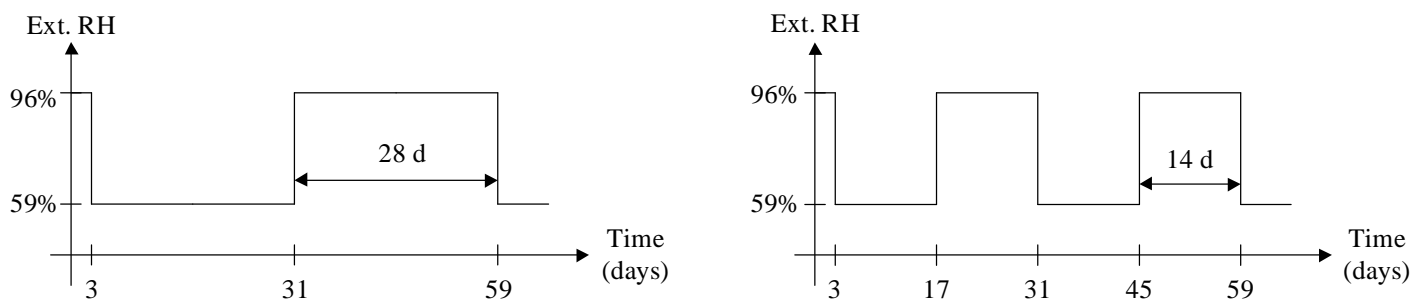

Fig. 4: long cycle (on the left) and short cycle (on the right)

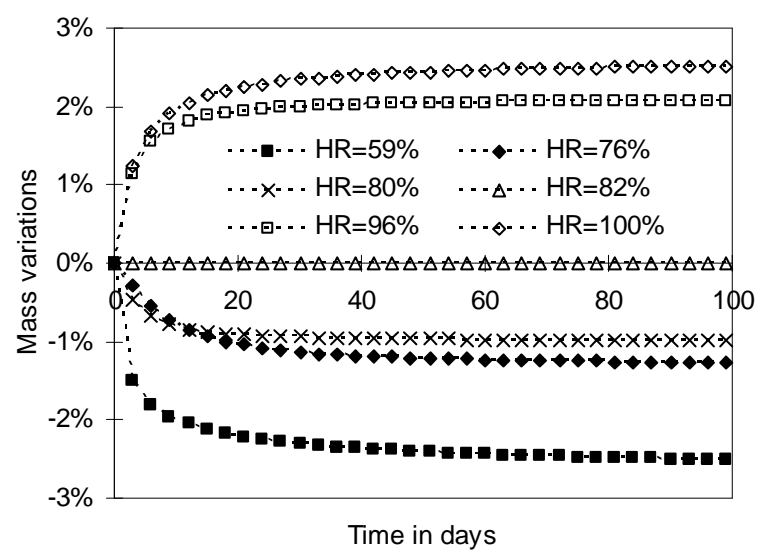

Fig. 5: mass variations for RH_constant specimens as a function of time and external relative humidity.

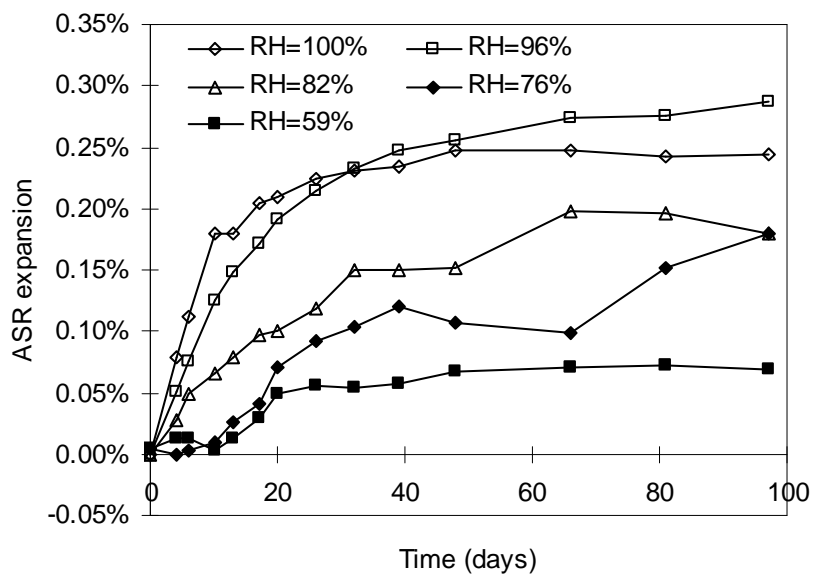

Fig. 6: ASR swelling versus time for different constant external relative humidities. 


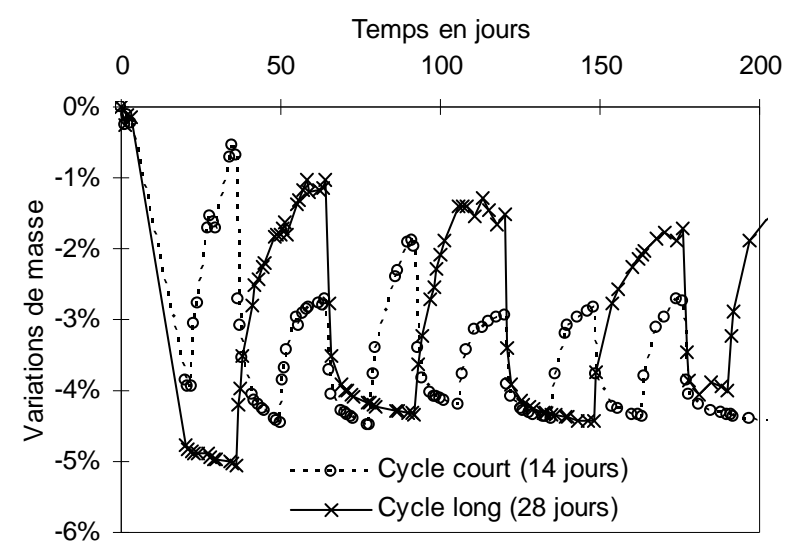

Fig. 7: mass variations for cyclic external relative humidity.

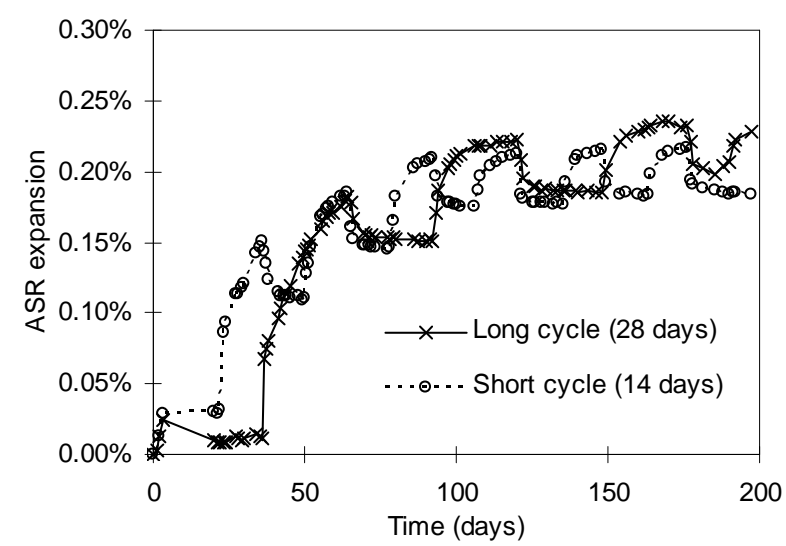

Fig. 8: ASR swelling versus time for cyclic relative humidity.

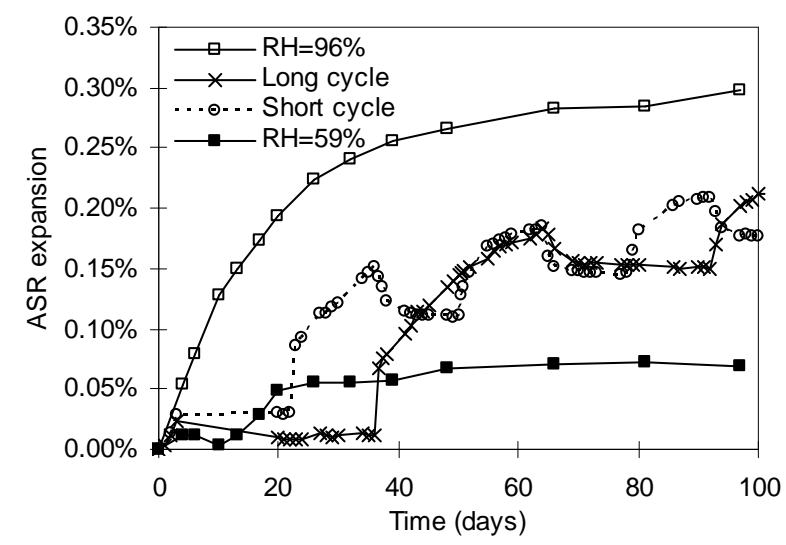

Fig. 9: ASR swelling comparison between constant and cyclic relative humidity. 


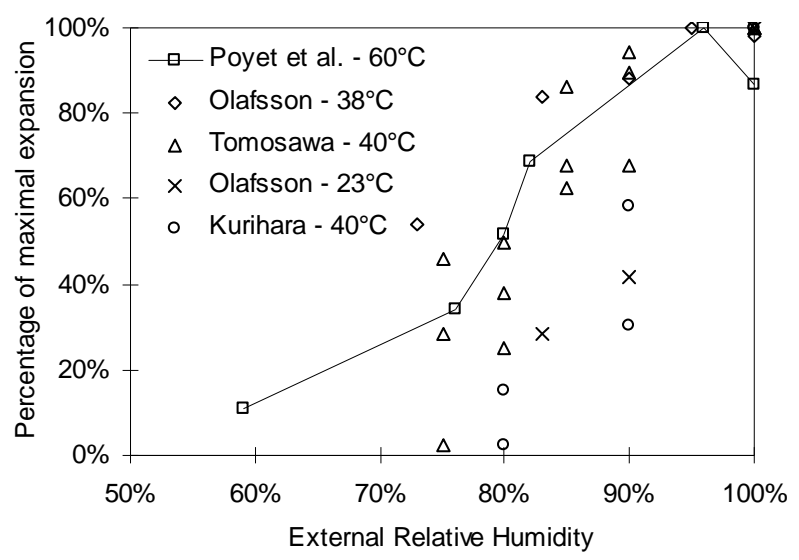

Fig. 10: evolution of maximal ASR expansion versus external relative humidity for several authors.

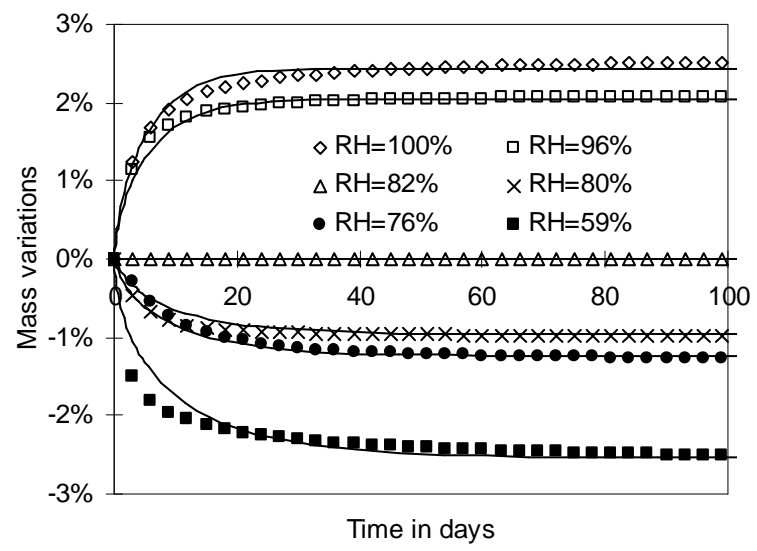

Fig. 11: comparison between simulated and experimental mass variations for constant RH experiments.

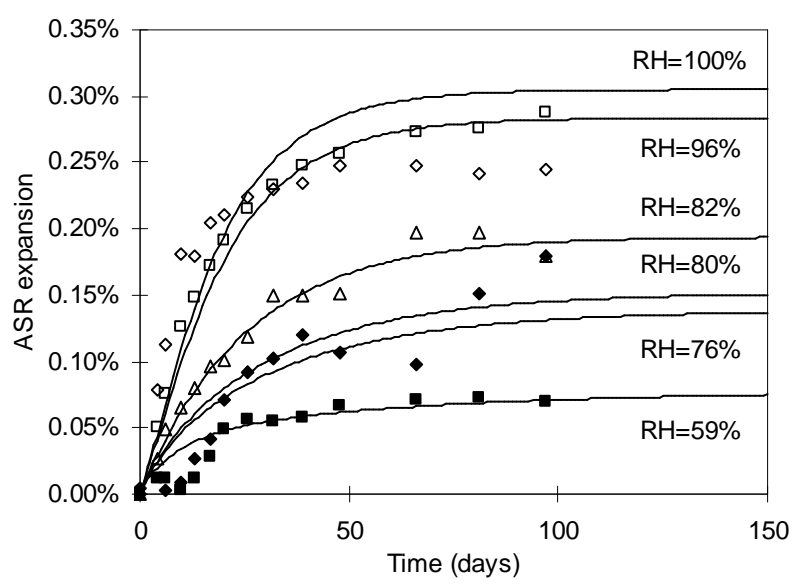

Fig. 12: comparison between predicted and experimental ASR swellings (irrelevant experimental results for $\mathrm{RH}=\mathbf{7 6} \%$ are not reproduced). 

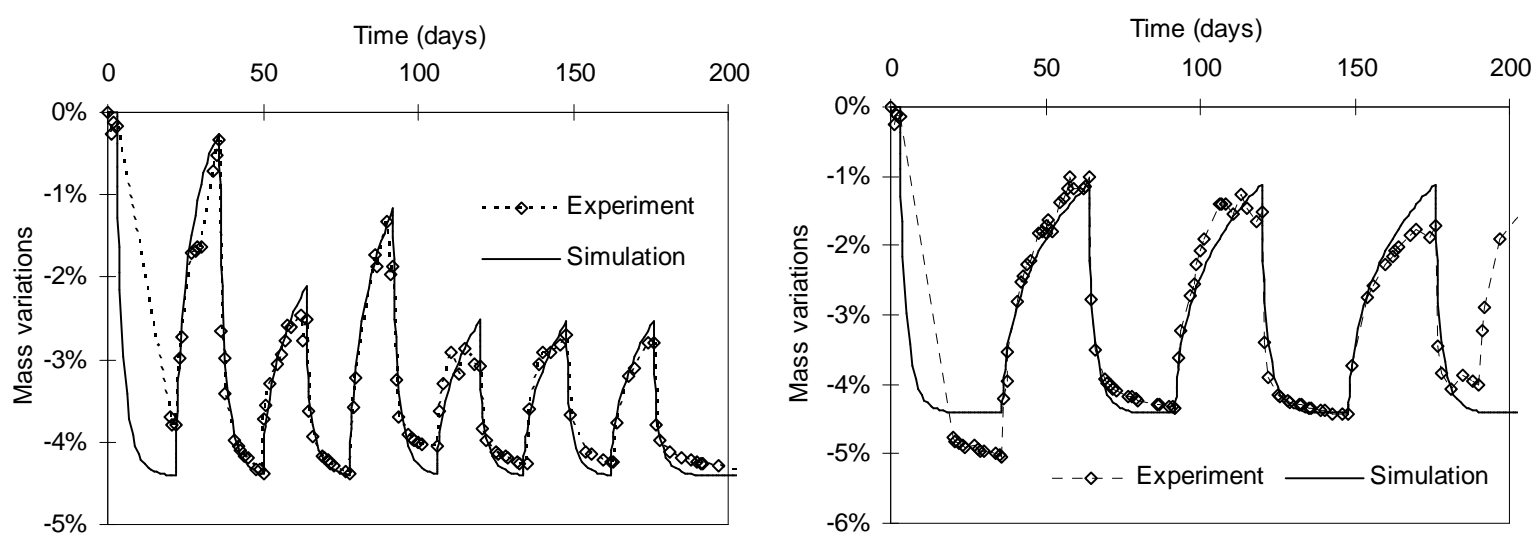

Fig. 13: comparison between experimental and simulated mass variations.
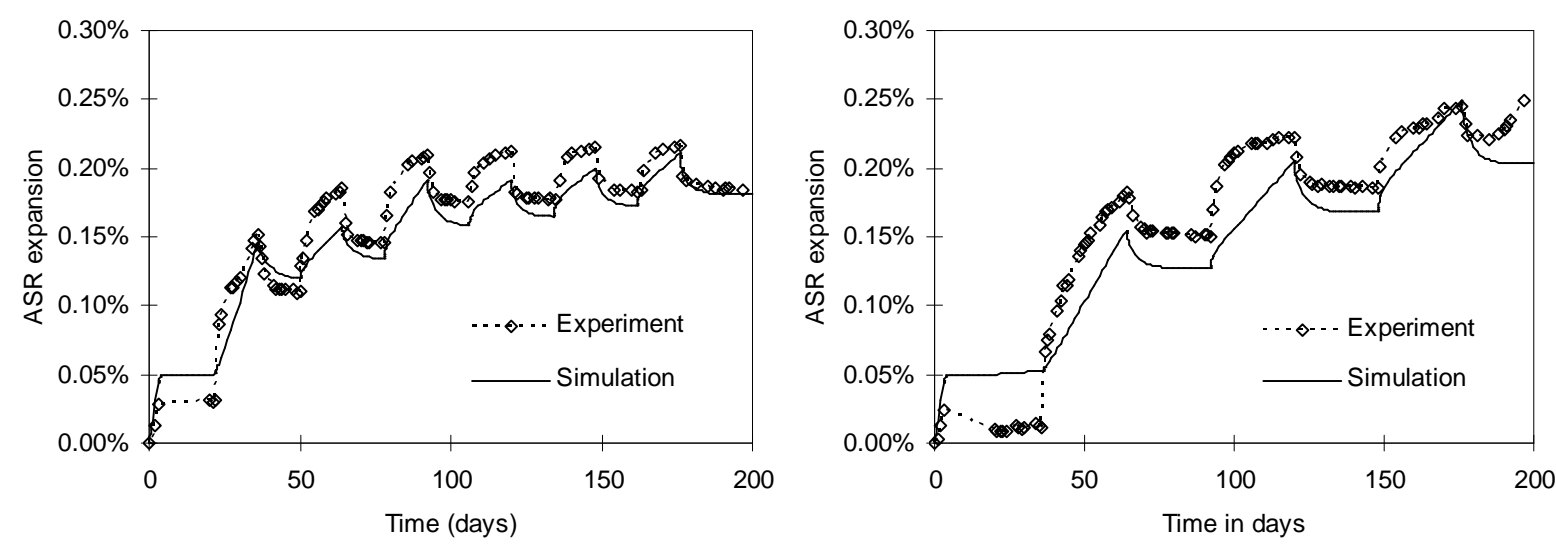

Fig. 14: Cyclic RH swelling simulations compared to experiments.
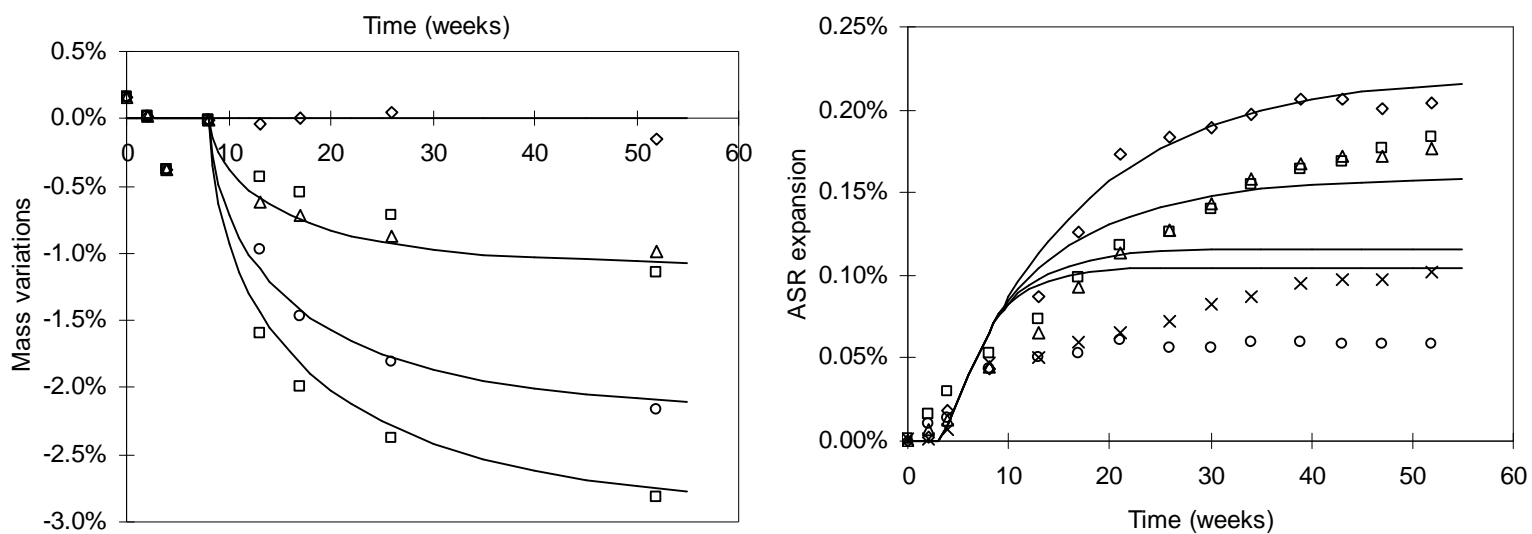

Fig. 15: Simulation of the experiments of Tomosawa et al. (1989). 

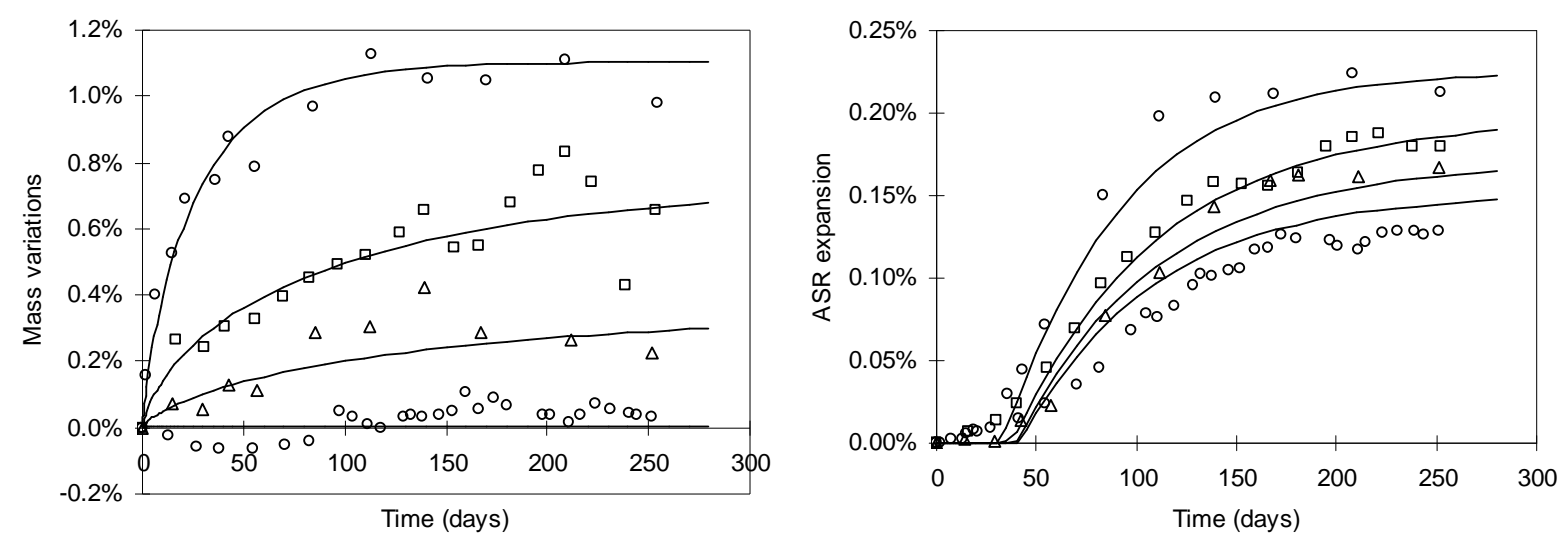

Fig. 16: simulation of the experiments of Larive et al. (2000). 